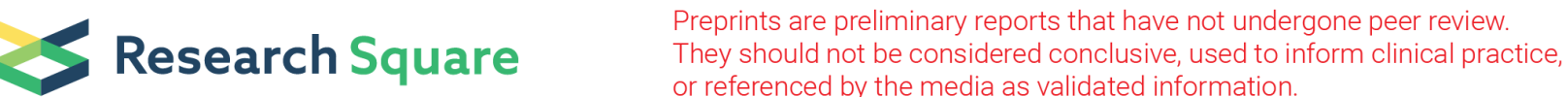

\section{Application of Calcium-rich Clay Mineral Under Nonwoven Fabric Mats and Sand Armor as Cap Layer for Interrupting $\mathbf{N}$ and $\mathrm{P}$ Release from River Sediments}

\author{
Seung-Hee Hong \\ Hankyong National University \\ Chang-Gu Lee \\ Ajou University \\ Seong-Jik Park ( $\sim$ parkseongjik@hknu.ac.kr) \\ Hankyong National University https://orcid.org/0000-0003-2122-5498
}

\section{Research Article}

Keywords: In-situ capping, Sediment, Calcium, Clay mineral, Phosphate, Nitrogen

Posted Date: January 3rd, 2022

DOI: https://doi.org/10.21203/rs.3.rs-1126422/v1

License: (c) (1) This work is licensed under a Creative Commons Attribution 4.0 International License. Read Full License

Version of Record: A version of this preprint was published at Environmental Science and Pollution Research on April 6th, 2022. See the published version at https://doi.org/10.1007/s11356-022-19998-y. 


\section{Abstract}

This work investigates the applicability of thermally treated calcium-rich clay minerals (CRCMs), such as sepiolite (SPL), attapulgite (ATT), and dolomite (DLM) to hinder the nitrogen (N) and phosphorus (P) release from river sediments. A non-woven fabric mat (NWFM) or a sand layer were also capped as armor layers, i.e., placed over CRCMs to investigate the capping impact on the N/P release. The capping efficiency was evaluated in a cylindrical reactor, consisting of CRCMs, armor layers, sediments, and sampled water. We monitored N/P concentrations, dissolved oxygen (DO), oxidation reduction potential, $\mathrm{pH}$, and electric conductivity in overlying water over 70 days. The DO concentrations in the uncapped and capped conditions were preserved for 30 days and 70 days (until the end of experiment duration), respectively. ATT showed higher efficiency for $\mathrm{NH}_{4}-\mathrm{N}$ and T-N than the other two materials, and the capping efficiency of $\mathrm{NH}_{4}-\mathrm{N}$ was measured as $96.4 \%, 93.7 \%$, and $61.6 \%$ when capped with $2 \mathrm{~cm}$ sand layer, $1 \mathrm{~cm}$ sand layer, and NWFM layer, respectively. DLM showed a superior rejection capability of $\mathrm{PO}_{4}-\mathrm{P}$ to ATT and SPL, reported as $97.2 \%$ when capped with $2 \mathrm{~cm}$ sand armor. The content of weakly adsorbed$P$ was lower in the uncapped condition than in the capping condition. It can be concluded that ATT and DLM can be used as capping agents to deactivate $\mathrm{N}$ and $\mathrm{P}$, respectively, to reduce water contamination from sediments of the eutrophic river.

\section{Introduction}

Phosphorus $(P)$ and nitrogen $(N)$, i. e., vital nutrients to living organisms in aquatic environments, often trigger eutrophication (Correll 1999; Zhu et al. 2019). Excessive P concentrations initiate eutrophication in freshwater resources such as lakes, reservoirs, streams, and the headwaters of estuarines, and eutrophication by excessive $\mathrm{N}$ is often observed in ocean environments (Correll 1999). These eutrophication phenomena degrade organic matter on sediment surfaces, deplete dissolved oxygens near the bottom of the water column, and accelerate the nutrient flux from sediments to the overlying water column (Holmboe et al. 2001). Once started, eutrophication can continue for several decades due to the internal nutrient loading from sediments (Yin et al. 2016; Zhan et al. 2019).

In situ capping is an effective method for mitigating potential water-body eutrophication by impeding the nutrient migration from polluted sediments to the water above them (Jiao et al. 2020). Compared to monitored natural recovery and dredging, this treatment method is less costly, less disruptive, and less time-consuming (Ghosh et al. 2011). In capping technology, a layer of material is placed on top of contaminated sediment as a physical barrier to prevent the contaminant release into the overlying layer and to sequester contaminants in sediments (Gu et al. 2017; Perelo 2010). The choice of suitable capping material is, therefore, of particular importance to mitigate the contaminant release and other environmental impacts (Zhu et al. 2019). Capping materials used in laboratories and field studies include activated carbon (Gu et al. 2017), phoslock (Wang et al. 2017), and natural/modified zeolites (Hong et al. 2019; Jacobs and Waite 2004; Xiong et al. 2018; Zhan et al. 2019). Other materials newly studied include apatite (Knox et al. 2014), attapulgite (ATT) (Yin et al. 2016), biochar (Wang et al. 2018; Zhu et al. 2019), 
calcium peroxide (Zhou et al. 2020), illite (Gu et al. 2019), layered double hydroxide (Wu et al. 2020), lanthanum-modified bentonite (Kong et al. 2020), and zero-valent iron (Todaro et al. in press).

In recent years, calcium-based materials have received close attention because of their high potential to inhibit the $P$ release from sediment, in addition to their straightforward implementation, costeffectiveness, and environmental-friendliness (Zhou et al. 2020). Necessary conditions of capping materials include high adsorption efficiency of targe contaminants, cost-effectiveness, and massproduction potential to cover large areas of contaminated sediments. In previous studies, calcium-rich clay minerals (CRCMs), such as sepiolite (SPL) (Hong et al. 2020), ATT (Kim et al. 2018a), and dolomite (DLM) (Kim et al. 2018b) were considered adequate for adsorbing phosphorus in aqueous solution, showing extra-potential of improved adsorption capacity by thermal treatment. In comparison to synthetic materials, the above-mentioned natural adsorbates are much more environmentally friendly as being used as effective capping materials for sediment remediation (Jacobs and Förstner 1999; Jacobs and Waite 2004).

A total of 16 large weirs along the four major rivers in South Korea, including the Han, Geum, Yeongsan, and Nakdong Rivers, were constructed between December 2008 and April 2012 as part of the Four Major Rivers Restoration Project (Jun and Kim 2011). The construction of artificial impoundments, such as dams or weirs, has altered carbon and nutrient fluxes from sediments and the deposition of sediments due to changes in hydrological flow (Chen et al. 2017). Although river-side weirs were constructed to secure water resources and mitigate seasonal floods, accumulated sediments due to the altered flow patterns seem to deteriorate the overlying water quality (Lee et al. 2018). The increase in hydraulic retention time by the impoundment may influence sedimentation of inorganic/organic nutrients and also the gradual change of stratification patterns (Fantin-Cruz et al. 2016).

In this work, we applied the new CRCMs to investigate their remediation potential for contaminated sediments formed by artificial impoundments and compared their capping efficiencies to interrupt the $\mathrm{N}$ and $P$ release from sediments to the overlying water. We compared the performance of sand and nonwoven fabric mat (NWFM) as armors of capping layers and monitored $\mathrm{T}-\mathrm{N}, \mathrm{NH}_{4}-\mathrm{N}, \mathrm{NO}_{3}-\mathrm{N}$, T-P, and $\mathrm{PO}_{4}-\mathrm{P}$ concentrations in overlying water, and calculated nutrient fluxes from the sediment layer to the overlying water. Other environmental parameters were also observed, such as $\mathrm{pH}$, oxidation reduction potential (ORP), electrical conductivity (EC), and dissolved oxygen (DO), to investigate any possible impacts or correlations to the capping-enhanced sediment remediation.

\section{Materials And Methods}

\subsection{Sampling for water and sediment}

We selected a sampling site at a location $\left(36^{\circ} 28^{\prime} 56^{\prime \prime}, 127^{\circ} 17^{\prime} 15^{\prime \prime}\right)$, i.e., about $6 \mathrm{~km}$ upstream of the Sejong weir (constructed in 2009), where Geum River is curved, resulting in sediment deposition. The sediments were collected using a Van Veen grab sampler and mechanically mixed to be uniform before 
use. We also sampled $40 \mathrm{~L}$ of river water using a polyvinyl chloride airtight container and subsequently filtered it using a GF/C filter ( $1.2 \mu \mathrm{m}$ pore size, Whatman, UK) to remove large debris and suspended particulates.

\subsection{Capping materials}

All the calcium-rich clay minerals, ATT and DLM (Rexem Co., Pohang, Korea) and SPL (Sigma-Aldrich), were sieved with a standard sieve No. $200(75 \mu \mathrm{m})$ to use upper-sized particles only. Thermal treatment under anoxic conditions was performed to improve the adsorption capacity of these materials using a tube furnace (CRFT 830S, Dongseo Science Co., Ltd., Korea), using optimal temperatures of ATT, DLM, and SPL, for the highest phosphate removal at $700^{\circ} \mathrm{C}, 900^{\circ} \mathrm{C}, 950^{\circ} \mathrm{C}$, respectively, (Kim et al. 2018a; Kim et al. 2018b; Hong et al. 2020). Their physicochemical properties and phosphate adsorption capacity can be found elsewhere (Hong et al. 2020; Kim et al. 2018a; Kim et al. 2018b), as summarized in Table 1. The NWFM samples (E\&H company, Pochon, Korea) have an average pore diameter of $15.64 \mu \mathrm{m}$ and a thickness of $300 \mu \mathrm{m}$, which were synthesized from polypropylene via the melt-blown method (E\&H Company). The clean sand (> $90 \%$ of $\mathrm{SiO}_{2}$, Jumunjin silica sand Co., Korea) was washed with deionized water before use as amour for the cap layer. 
Table 1

Physical properties, elemental composition, and adsorption capacity of calcium-rich clay minerals including sepiolite, attapulgite, and dolomite. Summarized from previous studies (Hong et al. 2020; Kim et al. 2018a; Kim et al. 2018b).

\begin{tabular}{|c|c|c|c|c|}
\hline & Sepiolite & Attapulgite & Dolomite \\
\hline & & $950^{\circ} \mathrm{C}$ & $700^{\circ} \mathrm{C}$ & $900^{\circ} \mathrm{C}$ \\
\hline \multicolumn{2}{|l|}{ Surface area $\left(\mathrm{m}^{2} / \mathrm{g}\right)$} & 7.66 & 69.8 & 8.41 \\
\hline \multicolumn{2}{|l|}{ Pore volume $\left(\mathrm{cm}^{3} / \mathrm{g}\right)$} & 0.08 & 0.24 & 0.05 \\
\hline \multicolumn{2}{|l|}{ Pore size $(\mathrm{nm})$} & 28.37 & 0.12 & 25.63 \\
\hline \multicolumn{2}{|l|}{ Bulk density } & 0.86 & 0.72 & 0.63 \\
\hline \multicolumn{2}{|l|}{$\mathrm{pH}$} & 12.88 & 10.40 & 11.39 \\
\hline \multirow[t]{6}{*}{ Elemental composition (\%) obtained by XRF } & $\mathrm{MgO}$ & 27.0 & 7.1 & 29.2 \\
\hline & $\mathrm{Al}_{2} \mathrm{O}_{3}$ & 1.8 & 20.7 & 2.6 \\
\hline & $\mathrm{SiO}_{2}$ & 35.3 & 53.7 & 19.8 \\
\hline & $\mathrm{K}_{2} \mathrm{O}$ & 0.3 & 2.9 & 0.0 \\
\hline & $\mathrm{CaO}$ & 34.1 & 6.1 & 43.3 \\
\hline & $\mathrm{Fe}_{2} \mathrm{O}_{3}$ & 0.0 & 5.8 & 2.2 \\
\hline \multirow[t]{3}{*}{ Adsorption capacity (mg/g) } & $\mathrm{NH}_{4}-\mathrm{N}$ & 0.52 & 0.6 & 11.74 \\
\hline & $\mathrm{NO}_{3}-\mathrm{N}$ & 0 & 0 & 0 \\
\hline & $\mathrm{PO}_{4}^{-} \mathrm{P}$ & 172.34 & 54.4 & 385.51 \\
\hline
\end{tabular}

\subsection{Lab-scale sediment incubation experiments}

Nine incubation experiments (three different capping adsorbents $\times$ three different armors) and two controls (uncapped condition) were performed to evaluate the efficiencies of ATT, DLM, and SPL to block the $\mathrm{N}$ and $\mathrm{P}$ release, as shown in Fig. 1. Four armoring conditions were applied to investigate the efficiency of capping materials: (1) no capping; (2) $1 \mathrm{~cm}$ capping of adsorbent under NWFM; (3) $1 \mathrm{~cm}$ capping of adsorbent under $1 \mathrm{~cm}$ sand armor; and (4) $1 \mathrm{~cm}$ capping of adsorbent under $2 \mathrm{~cm}$ sand armor. In the absence of capping materials or sand armor layers, sand was positioned below the sediments to make a total thickness of $9 \mathrm{~cm}$ and provide the same interval between the bottom of the water column and the sampling hole. Sediment incubation experiments were performed using a cylindrical tank with an inner radius of $7.5 \mathrm{~cm}$ and a depth of $25 \mathrm{~cm}$, and the sampling hole was positioned $10 \mathrm{~cm}$ above the base side. Through the sampling port, $30 \mathrm{~mL}$ of overlying water were obtained using a disposable syringe to analyze the concentrations of N and P. A DO meter (HI9146, Hanna Instruments, Romania) was 
implanted in the middle of the caps and sealed using silicone resin paste. The sampled river water of $3 \mathrm{~L}$ was injected into the cylindrical tank using a peristaltic pump (Model 7527-15, Cole-Parmer, USA) at a mild flow rate of $20 \mathrm{~mL} / \mathrm{min}$ to minimize any potential erosions of sediments and capping materials. The cylindrical tanks containing sediments, capping materials, and mixed water were maintained in an incubator (IB3-15, JEIO Tech Co., Korea) at a constant temperature of $25^{\circ} \mathrm{C}$ without lights for 70 days. Water was sampled at $1,2,3,7,14,21,28,42,54$, and 70 days after the initiation of the incubation to analyze environmental parameters ( $\mathrm{pH}, \mathrm{EC}, \mathrm{DO}$, and $\mathrm{ORP})$ and different $\mathrm{N}$ and $\mathrm{P}$ species concentrations $\left(\mathrm{NH}_{4}-\mathrm{N}, \mathrm{NO}_{3}-\mathrm{N}, \mathrm{T}-\mathrm{N}, \mathrm{PO}_{4}-\mathrm{P}\right.$, and $\left.\mathrm{T}-\mathrm{P}\right)$. The procedures for analyzing the nutrient concentration in sediments and overlying water were provided in Supplementary Information (Section 2.4.). The flux of nutrients per unit area during a day was calculated using Eq. S1. After the end of experiments, the four types of Pfraction (Adsorbed-P, Non-apatite inorganic $P$, Apatite-P, and Residual-P) under capping materials were analyzed using methods reported by Hieltjest and Lijklema (1980). The detailed procedure for analyzing each P-fraction was described in Supplementary Information (Section 2.5.).

\section{Results And Discussion}

\subsection{Properties of river water and sediments}

The properties and concentrations of the river water and sediments obtained from the sampling sites described in Section 2.1. are presented in Table S1. DO and T-P concentartaions were 8.71 and 0.13 $\mathrm{mg} / \mathrm{L}$, qualified to be Level 1 and Level 3 standard, respectively, by the Korean water quality standards (Level 1-6) for rivers. Both SS and TN concentrations were found to be highly contaminated as they are classified at Level 6 . The COD concentration in water is at Level 5 , and COD in sediments was within the moderate pollution range $(40,000-80,000 \mathrm{mg} / \mathrm{kg})$ by the United States Environmental Protection Agency (US EPA) sediment criteria. In the sediments, T-N and T-P contents were 2478 and $839 \mathrm{mg} / \mathrm{kg}$, respectively, which are below the sediment quality guidelines (T-N: $<5600 \mathrm{mg} / \mathrm{kg}$ and T-P: $<1600 \mathrm{mg} / \mathrm{kg}$, respectively) of the Korean Ministry of Environment, which is less strict than those of US EPA guidelines (T-N: $>2000$ $\mathrm{mg} / \mathrm{kg}$ and T-P: $>650 \mathrm{mg} / \mathrm{g}$, respectively). The organic matter content of the sampled sediments was measured as $9.98 \%$, which was higher than the $8 \%$, to be classified as seriously polluted sediment by US EPA guidelines. The high contents of organic matter, $\mathrm{N}$, and $\mathrm{P}$ in the sediments indicate that the nutrients in the sediments may be high enough to lead to eutrophication.

\subsection{Change of water environment parameters under different capping conditions}

Figure $\mathrm{S} 1$ shows variations of $\mathrm{DO}, \mathrm{pH}, \mathrm{EC}$, and ORP under the capping of CRCMs and armoring materials along with those in the uncapped condition for 70 days. The DO concentrations of uncapped sediment decreased continuously below $0.5 \mathrm{mg} / \mathrm{L}$ within 16 days and reached zero on day 30 , but those under capped conditions approached finite plateau values. The average concentrations of DO in the overlying water were in decreasing order (unit: $\mathrm{mg} / \mathrm{L}$ ): S1/SPL $(4.8 \pm 0.9)>\mathrm{S} 1 / \mathrm{DLM}(4.7 \pm 0.9)>\mathrm{S} 2 / \mathrm{DLM}(4.5 \pm 1.1)>$ S2/SPL $(4.4 \pm 1.2)>$ NWFM/SPL $(4.1 \pm 1.0)>$ S2/ATT $(4.0 \pm 1.6)>S 1 / A T T(3.6 \pm 1.5)>$ NWFM/DLM $(2.3 \pm 1.7)$ 
$>$ NWFM/ATT (1.6 \pm 2.0$)>$ UN-CAP $(0.9 \pm 1.8)$. Higher DO concentrations were observed in the overlying water above sand armor than NWFM because the thicker sand cap-layer retarded the DO depletion by interrupting organic matter release from sediments. The higher DO concentrations under capping conditions observed here indicate the valuable potential of capping materials for the remediation of eutrophic lake sediments. Our findings are supported by Yin and Kong (2015)'s work that managing higher DO concentrations in overlying water helps prevent the liberation of $\mathrm{P}$ from sediments, protect benthic animals, and restore submerged vegetation. Although the $\mathrm{pH}$ of UN-CAP was maintained at $\mathrm{pH}$ 7.7, the pHs of overlying-water under CRCMs capping conditions were observed higher than that of UNCAP. The $\mathrm{pH}$ increase under the capping condition was due to the alkaline nature of the capping materials: the dissolution of $\mathrm{Ca}^{2+}$ from CRCMs increases the $\mathrm{pH}$ of the overlying water as $\mathrm{Ca}$ is a base cation (Alvarado et al. 2020; McBride 1994). The decrease in pH under capping conditions from day 28 to day 70 indicates that the potential toxic effect associated with $\mathrm{pH}$ decreases over time. When the incubation experiments were finished, the $\mathrm{pH}$ under capping with SPL and DLM was measured about $\mathrm{pH}$ 11, much higher than that under ATT capping. The impact of ATT on the $\mathrm{pH}$ was not as significant as that of the other two materials. The EC under all experimental conditions increased slightly until day 14 , and that of UN-CAP was greater than that of the other capping conditions measured at the end of the experiment. The ORP (Eh) reduced during the first 28 days and subsequently rebounded with gradual increases. The ORP under SPL and DLM capping showed distinct behavior from that with ATT; the pH results also showed a similar feature.

\subsection{Release of nitrogen and phosphorus from uncapped/capped sediments to the overlying water}

Figure 2 shows concentrations of $\mathrm{T}-\mathrm{N}, \mathrm{NH}_{4}-\mathrm{N}$, and $\mathrm{NO}_{3}-\mathrm{N}$ in the overlying water released from sediments during the experiment period. In Figure 2(a), the T-N concentration of UN-CAP continuously increased up to $22.7 \mathrm{mg} / \mathrm{L}$; such an increase in T-N was also observed under the capping experiments except for S1/ATT and S2/ATT. In Figure 2(b), an increase in the $\mathrm{NH}_{4}-\mathrm{N}$ concentration was also observed under uncapped conditions. The ratio of $\mathrm{NH}_{4}-\mathrm{N} / \mathrm{T}-\mathrm{N}$ under uncapped conditions ranged from $16.2-94.3 \%$, and it was less than $50 \%$ at the beginning of incubation but higher than $75 \%$ after day 7 . A high fraction of $\mathrm{NH}_{4^{-}}$ $\mathrm{N}$ in the $\mathrm{N}$ of overlying water was also observed in other studies (Gu et al. 2017), who reported that the portion of $\mathrm{NH}_{4}-\mathrm{N}$ increased from 64.0 to $91.8 \%$ as the incubation time increased. The release of $\mathrm{N}$ from sediments, mainly as $\mathrm{NH}_{4}-\mathrm{N}$, may be attributed to the anaerobic condition after the depletion of DO ceased the nitrification of $\mathrm{NH}_{4}$ to $\mathrm{NO}_{3}$ (Beutel 2006; Lin et al. 2011). The higher amount of $\mathrm{NH}_{4}-\mathrm{N}$ released from uncapped sediments is consistent with the gradual decrease of $\mathrm{NO}_{3}-\mathrm{N}$ concentration that disappeared on Day 21. The nitrification process is considered halted under anaerobic conditions, leading to the buildup of $\mathrm{NH}_{4}$ in the pore water occupied in the sediment layer and ensuing discharge of $\mathrm{NH}_{4}$ into the overlying water (Beutel 2006). In the capping conditions with $\mathrm{DO}$ remained, $\mathrm{NO}_{3}$ release from capped sediments was retarded during the incubation experiments. 
The T-P and $\mathrm{PO}_{4}-\mathrm{P}$ concentrations in the overlying water during the incubation experiments are shown in Fig. 3. For the uncapped sediments, both T-P and $\mathrm{PO}_{4}-\mathrm{P}$ increased continuously throughout the incubation experiments. The T-P concentration under uncapped conditions increased up to $0.727 \mathrm{mg} / \mathrm{g}$, which can cause eutrophication and severe problems in water bodies. In most lakes, streams, reservoirs, and estuaries, $0.1 \mathrm{mg} / \mathrm{L}$ of T-P concentration is unacceptably high, and $0.02 \mathrm{mg} / \mathrm{L}$ of T-P often causes problems such as eutrophication (Correll 1998). Increases in T-P and $\mathrm{PO}_{4}-\mathrm{P}$ concentrations over time were also observed in the capped conditions, but these were lower than those of UN-CAP. The ratio of $\mathrm{PO}_{4}-\mathrm{P}$ and T-P in the uncapped condition ranged from $54.2-69.5 \%$, with an average of $69.5 \%$. The effect of the capping treatment for blocking the release of T-P and $\mathrm{PO}_{4}-\mathrm{P}$ is described in Section 3.4.

\subsection{Flux of nitrogen and phosphorus under different capping conditions}

The fluxes of $\mathrm{T}-\mathrm{N}, \mathrm{NH}_{4}-\mathrm{N}$, and $\mathrm{NO}_{3}-\mathrm{N}$ under different capping conditions were calculated, and the results are illustrated in Fig. 4. The flux of T-N in decreasing order are as follows: NWFM/SPL > NWFM/DLM > UN-CAP > S1/DLM > S1/SPL > S2/DLM > S2/SPL > NWFM/ATT > S1/ATT > S2/ATT. The T-N flux of NWFM/SPL and NWFM/DLM was higher than that of UN-CAP, indicating that the capping treatment using NWFM/SPL and NWFM/DLM was ineffective for blocking the release of T-N. In the case of ATT, a higher flux of T-N capped with NWFM when compared to the two different sand armor depths was also observed, similar to SPL and DLM. These results indicate that the sand armor shows better performance for blocking the release of T-N than NWFM, an observation that has also been noted by other researchers (Jiao et al. 2020; Lampert et al. 2011). The thicker the capping layer, the greater the diffusion distance between sediments and overlying water, and more time is required for nutrients to travel from sediments to overlying water (Jiao et al. 2020). A lower T-N flux for the $2 \mathrm{~cm}$ sand armor compared to the $1 \mathrm{~cm}$ sand armor was observed under all three different capping materials, and their difference corresponded to 4.4$9.0 \%$ of the T-N flux of UN-CAP. The effect of capping treatment on $\mathrm{NH}_{4}-\mathrm{N}$ flux was similar to that of T-N flux, and the flux of $\mathrm{NH}_{4}-\mathrm{N}$ in decreasing order is: UN-CAP $>\mathrm{NWFM} / \mathrm{SPL}>\mathrm{NWFM} / \mathrm{DLM}>\mathrm{S} 2 / \mathrm{DLM}>$ S1/DLM > S1/SPL > S2/SPL > NWFM/ATT > S1/ATT > S2/ATT. This result can be expected because the T-N released from sediment to overlying water was mainly composed of $\mathrm{NH}_{4}-\mathrm{N}$, as described above. The $\mathrm{NH}_{4}-\mathrm{N}$ flux of Ca-rich clay minerals under NWFM was also higher than that under sand armor, but the difference in $\mathrm{NH}_{4}-\mathrm{N}$ flux between sand armor depths of $1 \mathrm{~cm}$ and $2 \mathrm{~cm}$ was not significant.

A lower flux of $\mathrm{NH}_{4}-\mathrm{N}$ was observed under all capping treatments than UN-CAP, and the $\mathrm{NH}_{4}-\mathrm{N}$ fluxes of ATT were lower than those of the other two capping materials. This result can be explained by higher adsorption capacity $\left(11.74 \mathrm{mg} / \mathrm{g}\right.$ ) of ATT for $\mathrm{NH}_{4}-\mathrm{N}$ than the other two materials (SPL: $0.60 \mathrm{mg} / \mathrm{L}$; DLM: $0.52 \mathrm{mg} / \mathrm{L}$ ). Ammonium can be removed from water by ATT through electrostatic adsorption and ion exchange (Sun et al. 2017). 
The fluxes of T-P and $\mathrm{PO}_{4}-\mathrm{P}$ under uncapped and capped with different Ca-rich clay minerals and armors are presented in Fig. 5. The lower T-P flux under capping conditions than UN-CAP indicates that all capping materials used in this study were useful for interrupting T-P release from sediments. Similar to T$\mathrm{P}$, the effect of capping was also observed in the reduction of the $\mathrm{PO}_{4}-\mathrm{P}$ flux. This result was expected because the T-P in the overlying water accounted for approximately $70 \%$ of T-P, as described in Section 3.3. For all capping materials, sand armor with a depth of $2 \mathrm{~cm}$ was more effective than $1 \mathrm{~cm}$. In contrast to $\mathrm{NH}_{4}-\mathrm{N}$ and T-N fluxes, the T-P and $\mathrm{PO}_{4}-\mathrm{P}$ fluxes between the sand armor and NWFM did not show significant differences, and the $\mathrm{PO}_{4}-\mathrm{P}$ and T-P fluxes of SPL with $1 \mathrm{~cm}$ of sand were higher than those of SPL with NWFM. The negatively charged surface of the sand was not adequate for adsorbing the anion $\mathrm{PO}_{4}{ }^{3-}$, but the sand layer blocked the release of $\mathrm{PO}_{4}-\mathrm{P}$ only by acting as a physical barrier interrupting $\mathrm{PO}_{4}-\mathrm{P}$ diffusion. Compared to the flux of $\mathrm{T}-\mathrm{N}$ and $\mathrm{NH}_{4}-\mathrm{N}$, the fluxes of T-P and $\mathrm{PO}_{4}-\mathrm{P}$ showed a significant difference of capping material. ATT was the most effective capping material for interrupting the release of T-N and $\mathrm{NH}_{4}-\mathrm{N}$; however, it was less effective for T-P and $\mathrm{PO}_{4}-\mathrm{P}$ than SPL and DLM. This result is also consistent with the order of the $\mathrm{PO}_{4}-\mathrm{P}$ adsorption capacity of Ca-rich clay minerals, as shown in Table 1. The adsorption capacity for $\mathrm{PO}_{4}-\mathrm{P}$ follows in decreasing order: $\mathrm{DLM}(385.5 \mathrm{mg} / \mathrm{g})>\mathrm{SPL}(172.3 \mathrm{mg} / \mathrm{g})>$ ATT $(54.5 \mathrm{mg} / \mathrm{g})$, and this order is inverse proportional to the order of $\mathrm{PO}_{4}-\mathrm{P}$ flux and proportionate to the blocking efficiency of $\mathrm{PO}_{4}-\mathrm{P} . \mathrm{Ca}^{2+}$ eluted from SPL and DLM can enhance the removal of $\mathrm{PO}_{4}{ }^{3-}$ in the overlying water by forming calcium-bound $\mathrm{P}(\mathrm{Ca}-\mathrm{P}$ ) precipitation (Hong et al. 2020; Kim et al. 2018b; Yin et al. 2013).

\subsection{Effect of capping treatment on the $P$ fractions in sediments}

The $\mathrm{P}$ fractions, including Adsorbed-P, NAI-P, Apatite-P, and Residual-P of sediment under different capping treatments, are presented in Fig. 6(a). Under all experimental conditions, most of the $P$ in the sediment was present in the form of NAI-P and Residual-P, and the Adsorbed-P, a weakly adsorbed state, accounts for less than $1 \%$ of the total amount of $\mathrm{P}$ in sediments. The content of Absorbed-P in UN-CAP was $5.5 \mathrm{mg} / \mathrm{kg}$ (Fig. $6(\mathrm{~b})$, which is equal to $0.5 \%$ of the T-P. The lower fraction of Adsorbed-P in UN-CAP compared to other conditions can be explained by a more incredible amount of $\mathrm{P}$ released from sediments into the overlying water, as shown in Fig. 3. A lower Adsorbed-P fraction was also observed under ATT capping than under SPL and DLM capping. This result is also consistent with the higher release of $\mathrm{P}$ to the overlying water under ATT capping than the other two Ca-rich clay minerals. Under all capping conditions, the fraction of NAl-P was bound to $\mathrm{Al} / \mathrm{Fe}$ and released from sediments under anaerobic conditions (Hong et al. 2020; Kaiserli et al. 2002). The Residual-P fraction, the most stable form of $\mathrm{P}$ and not readily released to overlying water, increased up to $>80 \%$ under all capping conditions, indicating that the less stable $P$ was converted to Residual-P through the Ca-rich capping treatment. The $\mathrm{P}$ fraction showed a distinct difference according to the Ca-rich clay mineral used, but not the armor used. The $2 \mathrm{~cm}$ of sand armor showed the highest Residual-P fraction for SPL and DLM, but the lowest Residual-P fraction was observed under ATT. 


\section{Conclusions}

The results suggest that the application of Ca-rich clay minerals can remediate sediments deposited by the construction of artificial impoundments. The effectiveness of the sand layer and NWFM were also evaluated as armor materials. While DO was depleted under the uncapped condition on Day 30, the DO under all capping conditions was preserved during the 70 days of the incubation experiment. The $\mathrm{pH}$ under the use of SPL and DLM significantly increased, and the pH of ATT was slightly higher than that of UN-CAP. The ATT effectively blocked the liberation of $\mathrm{T}-\mathrm{N}$ and $\mathrm{NH}_{4}-\mathrm{N}$ from sediments by adsorbing ammonia via ion exchange. Less $\mathrm{PO}_{4}-\mathrm{P}$ and T-P from sediments were released from sediment capped with DLM than the other materials, which is attributed to the higher adsorption capacity of DLM for $\mathrm{PO}_{4}{ }^{3-}$. A thicker sand layer retarded the release of $\mathrm{N}$ and $\mathrm{P}$ from sediments by increasing the diffusion distance between the sediments and the overlying water. Higher Residual-P and lower Adsorbed-P fractions were obtained using Ca-rich clay mineral capping than under uncapped conditions, indicating that $P$ sequestration by capping was feasible. ATT is a useful capping material for interrupting $\mathrm{N}$ release whilst not having a significant influence on the $\mathrm{pH}$. Owing to its low blocking efficiency of the $\mathrm{P}$ release, however, ATT should be mixed with a material such as DLM, which has excellent $P$ adsorption capacity.

\section{Declarations}

Conflicts of interest: The authors declare that they have no competing interests

Authors' contributions

Seung-Hee Hong: Conceptualization, Experiment, Data analysis; Chang-Gu Lee: Writing-review and editing; Seong-Jik Park: Conceptualization, Writing-original draft; Writing-review \& editing, Supervision, Funding acquisition

Funding

This work was supported by a National Research Foundation of Korea (NRF) grant funded by the Korean government (MSIT) (No. 2020R1C1C1008982).

Ethics approval and consent to participate: Not applicable

Consent for publication: Not applicable

Consent for participation: Not applicable

Availability of data and materials

All data generated or analysed during this study are included in this published article. 
The datasets used and/or analysed during the current study are available from the corresponding author on reasonable request.

\section{References}

Alvarado JN, Hong SH, Lee CG, Park SJ (2020) Comparison of capping and mixing of calcined dolomite and zeolite for interrupting the release of nutrients from contaminated lake sediment. Environ Sci Pollut $R$ 1-12. https://doi.org/10.1007/s11356-020-08058-y

Beutel MW (2006) Inhibition of ammonia release from anoxic profundal sediments in lakes using hypolimnetic oxygenation. Ecol Eng 28: 271-279. https://doi.org/10.1016/j.ecoleng.2006.05.009

Chen M, Kim SH, Jung HJ, Hyun JH, Choi JH, Lee HJ, Hur J (2017) Dynamics of dissolved organic matter in riverine sediments affected by weir impoundments: Production, benthic flux, and environmental implications. Water Res 121: 150-161. https://doi.org/10.1016/j.watres.2017.05.022

Correll DL (1998) The role of phosphorus in the eutrophication of receiving waters: A review. J Environ Qual 27: 261-266. https://doi.org/10.2134/jeq1998.00472425002700020004x

Correll DL (1999) Phosphorus: a rate limiting nutrient in surface waters. Poultry Sci 78: 674682. https://doi.org/10.1093/ps/78.5.674

Fantin-Cruz I, Pedrollo O, Girard P, Zeilhofer P, Hamilton SK. (2016) Changes in river water quality caused by a diversion hydropower dam bordering the Pantanal floodplain. Hydrobiologia 768: 223238. https://doi.org/10.1007/s10750-015-2550-4

Ghosh U, Luthy RG, Cornelissen G, Werner D, Menzie CA (2011) In-situ sorbent amendments: a new direction in contaminated sediment management. Environ Sci Technol 45: 11631168. https://doi.org/10.1021/es102694h

Gu BW, Lee CG, Lee TG, Park SJ (2017) Evaluation of sediment capping with activated carbon and nonwoven fabric mat to interrupt nutrient release from lake sediments. Sci Total Environ 599: 413421. https://doi.org/10.1016/j.scitotenv.2017.04.212

Gu BW, Hong SH, Lee CG, Park SJ (2019) The feasibility of using bentonite, illite, and zeolite as capping materials to stabilize nutrients and interrupt their release from contaminated lake sediments.

Chemosphere 219: 217-226. https://doi.org/10.1016/j.chemosphere.2018.12.021

Hieltjes AH, Lijklema L (1980) Fractionation of inorganic phosphates in calcareous sediments. J Environ Qual 9: 405-407. https://doi.org/10.2134/jeq1980.00472425000900030015x

Holmboe N, Kristensen E, Andersen F Ø (2001) Anoxic decomposition in sediments from a tropical mangrove forest and the temperate Wadden Sea: implications of $\mathrm{N}$ and $\mathrm{P}$ addition experiments. Estuar Coast Shelf Sci 53: 125-140. https://doi.org/10.1006/ecss.2000.0794 
Hong SH, Lee JI, Lee CG, Park SJ (2019) Effect of temperature on capping efficiency of zeolite and activated carbon under fabric mats for interrupting nutrient release from sediments. Sci Rep 9: 111. https://doi.org/10.1038/s41598-019-52393-1

Hong SH, Ndingwan AM, Yoo SC, Lee CG, Park SJ (2020) Use of calcined sepiolite in removing phosphate from water and returning phosphate to soil as phosphorus fertilizer. J Environ Manag 270:

110817. https://doi.org/10.1016/j.jenvman.2020.110817

Jacobs PH, Förstner U (1999) Concept of subaqueous capping of contaminated sediments with active barrier systems (ABS) using natural and modified zeolites. Water Res 33: 2083-

2087. https://doi.org/10.1016/S0043-1354(98)00432-1

Jacobs PH, Waite TD (2004) The role of aqueous iron (II) and manganese (II) in sub-aqueous active barrier systems containing natural clinoptilolite. Chemosphere 54: 313-

324. https://doi.org/10.1016/S0045-6535(03)00751-3

Jiao Y, Xu L, Li Q, Gu S (2020) Thin-layer fine-sand capping of polluted sediments decreases nutrients in overlying water of Wuhan Donghu Lake in China. Environ Sci Pollut R 27: 7156-

7165. https://doi.org/10.1007/s11356-019-07297-y

Jun KS, Kim JS (2011) The four major rivers restoration project: impacts on river flows. KSCE J Civ Eng 15: 217-224. https://doi.org/10.1007/s12205-011-0002-x

Kaiserli A, Voutsa D, Samara C (2002) Phosphorus fractionation in lake sediments-Lakes Volvi and Koronia, N. Greece. Chemosphere 46: 1147-1155. https://doi.org/10.1016/S0045-6535(01)00242-9

Kim MJ, Lee JI, Lee CG, Park SJ (2018a) Thermal treatment of attapulgite for phosphate removal: a cheap and natural adsorbent with high adsorption capacity. Desalin Water Treat 114, 175-

184. http://doi.org/10.5004/dwt.2018.22409

Kim MJ, Lee Jl, Park SJ (2018b) Manufacture of high efficiency phosphate adsorbent by thermal treatment of dolomite. Journals of Korean Society of Water Science and Technology 26: 69-78

Knox AS, Paller MH, Dixon KL (2014) Evaluation of active cap materials for metal retention in sediments. Remediation Journal 24: 49-69. https://doi.org/10.1002/rem.21394

Kong M, Liu F, Tao Y, Wang P, Wang C, Zhang Y (2020) First attempt for in situ capping with lanthanum modified bentonite (LMB) on the immobilization and transformation of organic phosphorus at the sediment-water interface. Sci Total Environ 741:

140342. https://doi.org/10.1016/j.scitotenv.2020.140342

Lampert DJ, Sarchet WV, Reible DD (2011) Assessing the effectiveness of thin-layer sand caps for contaminated sediment management through passive sampling. Environ Sci Technol 45: 84378443. https://doi.org/10.1021/es200406a

Page $12 / 20$ 
Lee MH, Jung HJ, Kim SH, An SU, Choi JH, Lee HJ, Hur J (2018) Potential linkage between sediment oxygen demand and pore water chemistry in weir-impounded rivers. Sci Total Environ 619: 16081617. https://doi.org/10.1016/j.scitotenv.2017.10.141

Lin J, Zhan Y, Zhu Z (2011) Evaluation of sediment capping with active barrier systems (ABS) using calcite/zeolite mixtures to simultaneously manage phosphorus and ammonium release. Sci Total Environ 409: 638-646. https://doi.org/10.1016/j.scitotenv.2010.10.031

McBride MB (1994) Environmental chemistry of soils. Oxford University Press, New York

Perelo LW (2010) In situ and bioremediation of organic pollutants in aquatic sediments. J Hazard Mater 177: 81-89. https://doi.org/10.1016/j.jhazmat.2009.12.090

Schaanning M, Breyholtz B, Skei J (2006) Experimental results on effects of capping on fluxes of persistent organic pollutants (POPs) from historically contaminated sediments. Mar Chem 102: 4659. https://doi.org/10.1016/j.marchem.2005.10.027

Sun N, Shi W, Ma L, Yu S (2017) Investigations on the mechanism, kinetics and isotherms of ammonium and humic acid co-adsorption at low temperature by $4 \mathrm{~A}$-molecular sieves modified from attapulgite. RSC advances 7: 17095-17106. https://doi.org/10.1039/C7RA00268H

Todaro F, Barjoveanu G, De Gisi S, Teodosiu C, Notarnicola M (2020) Sustainability assessment of reactive capping alternatives for the remediation of contaminated marine sediments. J Clean Prod 124946. https://doi.org/10.1016/j.jclepro.2020.124946

Wang C, He R, Wu Y, Lürling M, Cai H, Jiang HL, Liu X (2017) Bioavailable phosphorus (P) reduction is less than mobile $\mathrm{P}$ immobilization in lake sediment for eutrophication control by inactivating agents. Water Res 109: 196-206. https://doi.org/10.1016/j.watres.2016.11.045

Wang M, Zhu Y, Cheng L, Andserson B, Zhao X, Wang D, Ding A (2018) Review on utilization of biochar for metal-contaminated soil and sediment remediation. J Environ Sci 63: 156-

173. https://doi.org/10.1016/j.jes.2017.08.004

Wu J, Lin J, Zhan Y (2020) Interception of phosphorus release from sediments using Mg/Fe-based layered double hydroxide (MF-LDH) and MF-LDH coated magnetite as geo-engineering tools. Sci Total Environ 739: 139749. https://doi.org/10.1016/j.scitotenv.2020.139749

Xiong C, Wang D, Tam NF, Dai Y, Zhang X, Tang X, Yang Y (2018) Enhancement of active thin-layer capping with natural zeolite to simultaneously inhibit nutrient and heavy metal release from sediments. Ecol Eng 119: 64-72. https://doi.org/10.1016/j.ecoleng.2018.05.008

Yin H, Kong M, Fan C (2013) Batch investigations on P immobilization from wastewaters and sediment using natural calcium rich sepiolite as a reactive material. Water Res 47: 42474258. https://doi.org/10.1016/j.watres.2013.04.044 
Yin H, Kong M (2015) Reduction of sediment internal P-loading from eutrophic lakes using thermally modified calcium-rich attapulgite-based thin-layer cap. J Environ Manage 151: 178-

185. https://doi.org/10.1016/j.jenvman.2015.01.003

Yin H, Han M, Tang W (2016) Phosphorus sorption and supply from eutrophic lake sediment amended with thermally-treated calcium-rich attapulgite and a safety evaluation. Chem Eng J 285: 671-

678. https://doi.org/10.1016/j.cej.2015.10.038

Zhan Y, Yu Y, Lin J, Wu X, Wang Y, Zhao Y (2019) Simultaneous control of nitrogen and phosphorus release from sediments using iron-modified zeolite as capping and amendment materials. J Environ Manage 249: 109369. https://doi.org/10.1016/j.jenvman.2019.109369

Zhou J, Li D, Zhao Z, Song X, Huang Y, Yang J (2020) Phosphorus immobilization by the surface sediments under the capping with new calcium peroxide material. J Clean Prod 247:

119135. https://doi.org/10.1016/j.jclepro.2019.119135

Zhu Y, Tang W, Jin X, Shan B (2019) Using biochar capping to reduce nitrogen release from sediments in eutrophic lakes. Sci Total Environ 646: 93-104. https://doi.org/10.1016/j.scitotenv.2018.07.277

\section{Figures}
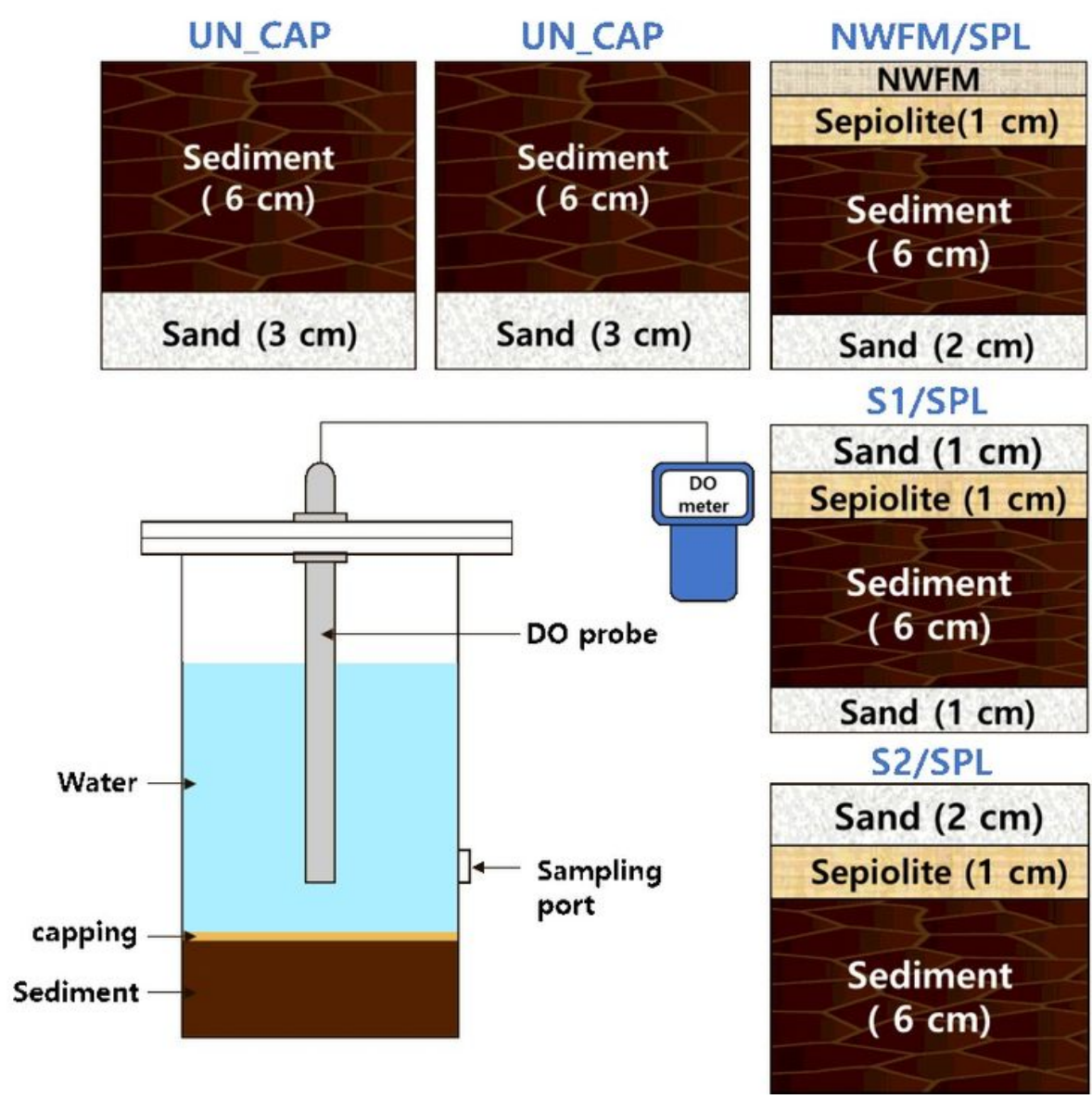

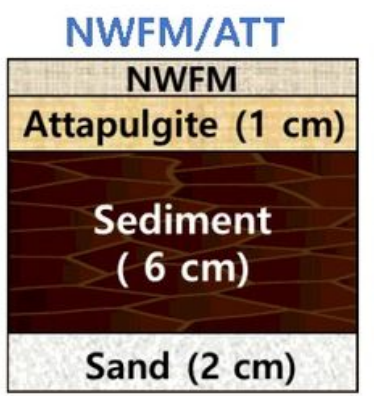

S1/ATT

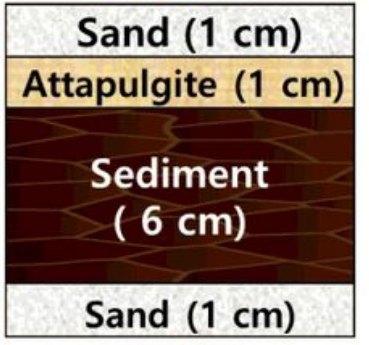

S2/ATT

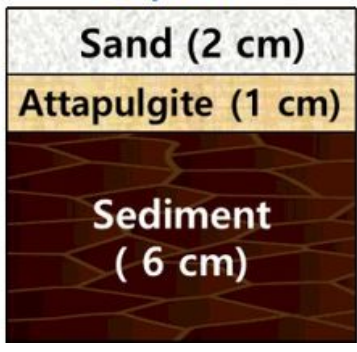

NWFM/DLM NWFM

Dolomite $(1 \mathrm{~cm})$

\begin{tabular}{|c|}
\hline Sediment \\
\hline$(6 \mathrm{~cm})$ \\
\hline Sand $(2 \mathrm{~cm})$ \\
\hline
\end{tabular}

S1/DLM

\begin{tabular}{|c|}
\hline Sand $(1 \mathrm{~cm})$ \\
\hline Dolomite $(1 \mathrm{~cm})$ \\
\hline Sediment \\
\hline$(6 \mathrm{~cm})$ \\
\hline Sand $(1 \mathrm{~cm})$ \\
\hline S2/DLM \\
\hline Sand $(2 \mathrm{~cm})$ \\
\hline Dolomite $(1 \mathrm{~cm})$ \\
\hline \\
\hline Sediment \\
\hline$(6 \mathrm{~cm})$ \\
\hline
\end{tabular}


Figure 1

Schematic diagram of the experimental setup
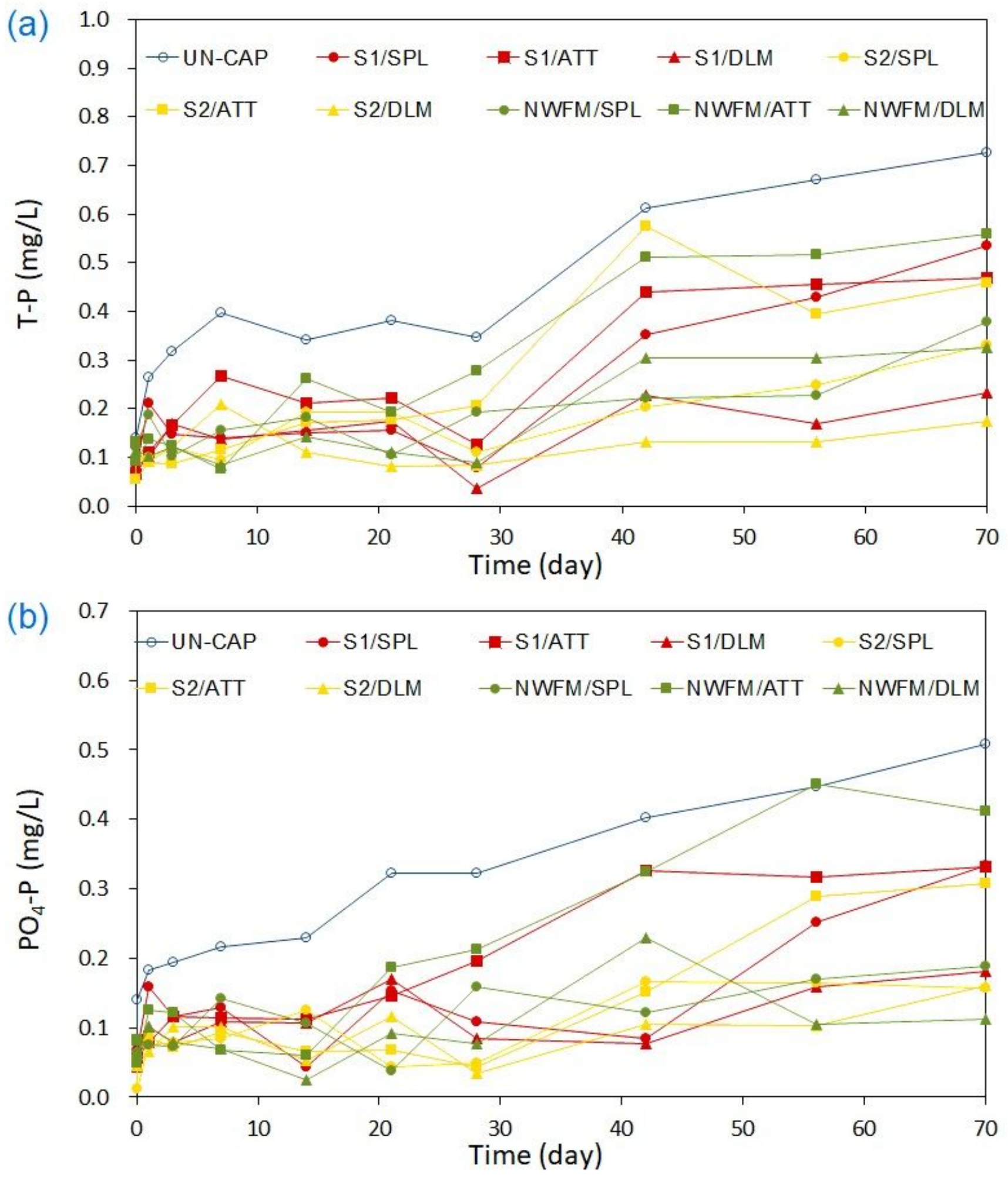

Figure 2 
Changes in (a) $\mathrm{T}-\mathrm{N}(\mathrm{mg} / \mathrm{L})$, (b) $\mathrm{NH}_{4}-\mathrm{N}(\mathrm{mg} / \mathrm{L})$, and (c) $\mathrm{NO}_{3}-\mathrm{N}(\mathrm{mg} / \mathrm{L}$ ) concentration in the water overlying sediment (UN-CAP), different Ca-rich clay minerals (SPL, ATT, and DLM), and armor materials (S1, S2, and NWFM) during 70 days of laboratory incubations.
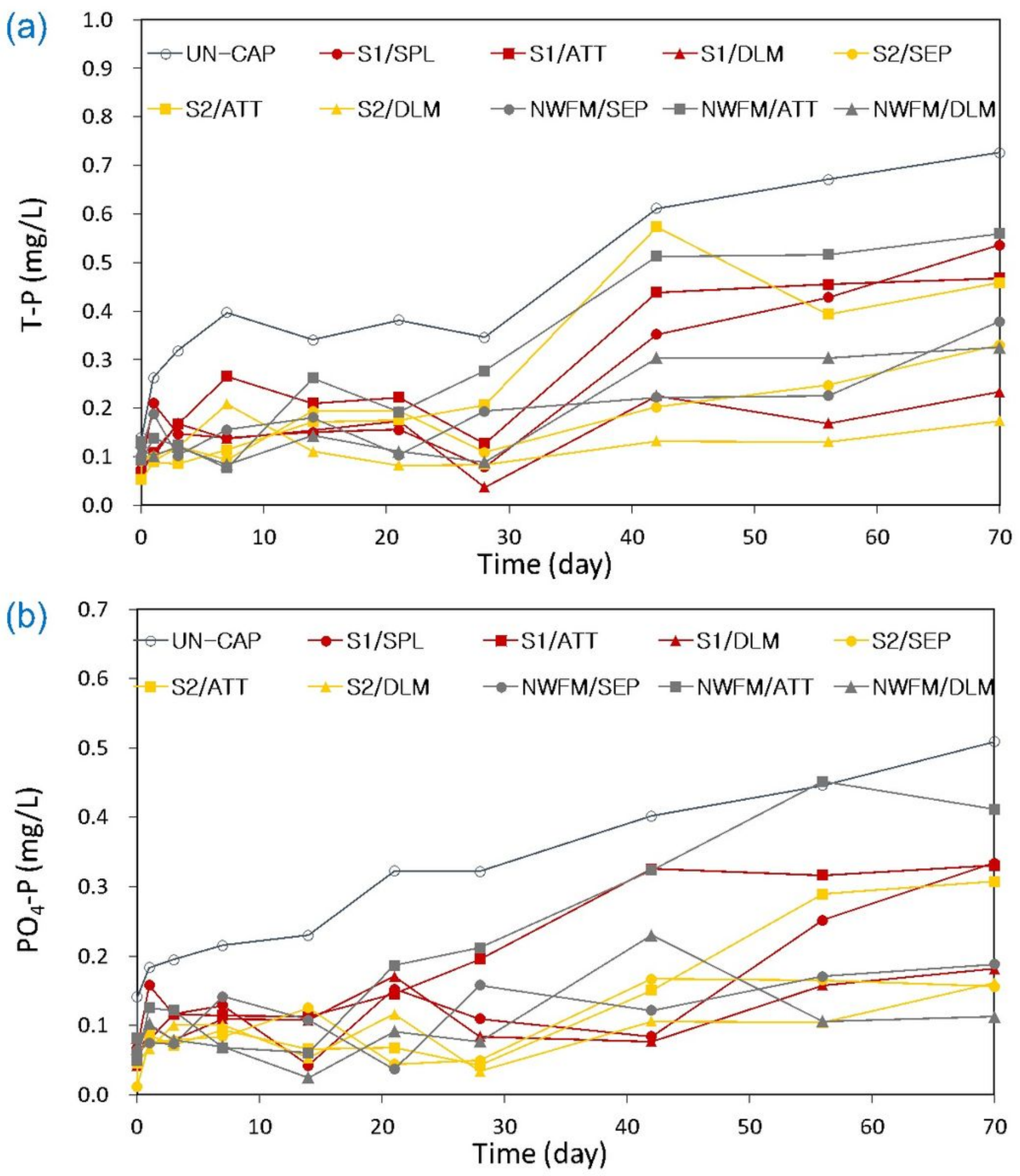

Figure 3 
Changes in (a) T-P (mg/ $\mathrm{L}$ ) and (b) $\mathrm{PO}_{4}-\mathrm{P}(\mathrm{mg} / \mathrm{L})$ concentration in the water overlying sediment (UN-CAP), different Ca-rich clay minerals (SPL, ATT, and DLM), and armor materials (S1, S2, and NWFM) during 70 days of laboratory incubations.
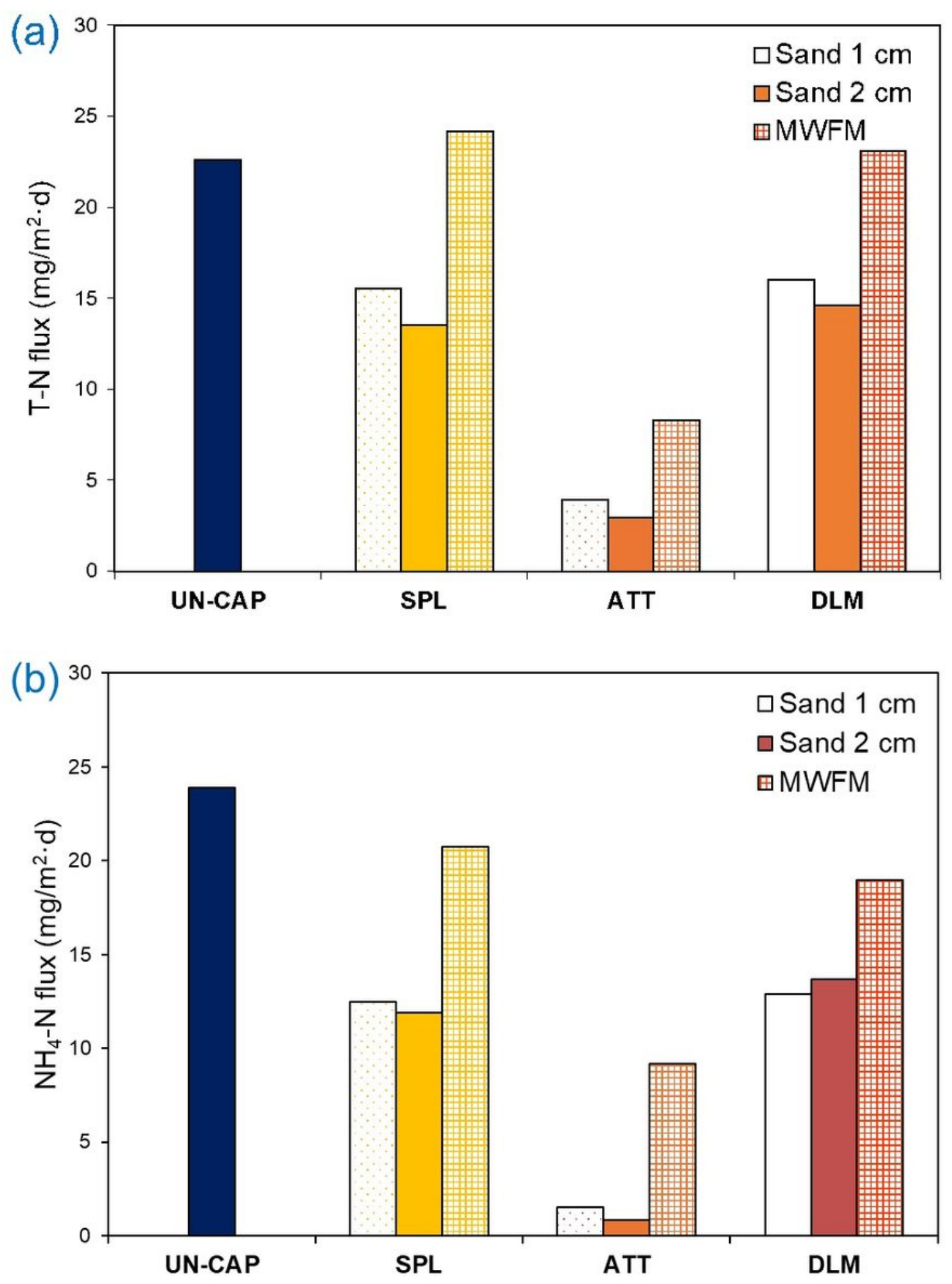

Figure 4 
Flux $\left(\mathrm{mg} / \mathrm{m}^{2} \cdot \mathrm{d}\right.$ ) of (a) $\mathrm{T}-\mathrm{N}$ and (b) $\mathrm{NH}_{4}-\mathrm{N}$ from sediments to overlying water under the uncapped condition and capped conditions with different Ca-rich clay minerals (SPL, ATT, and DLM) and armor materials (S1, S2, and NWFM) during 70 days of laboratory incubations.
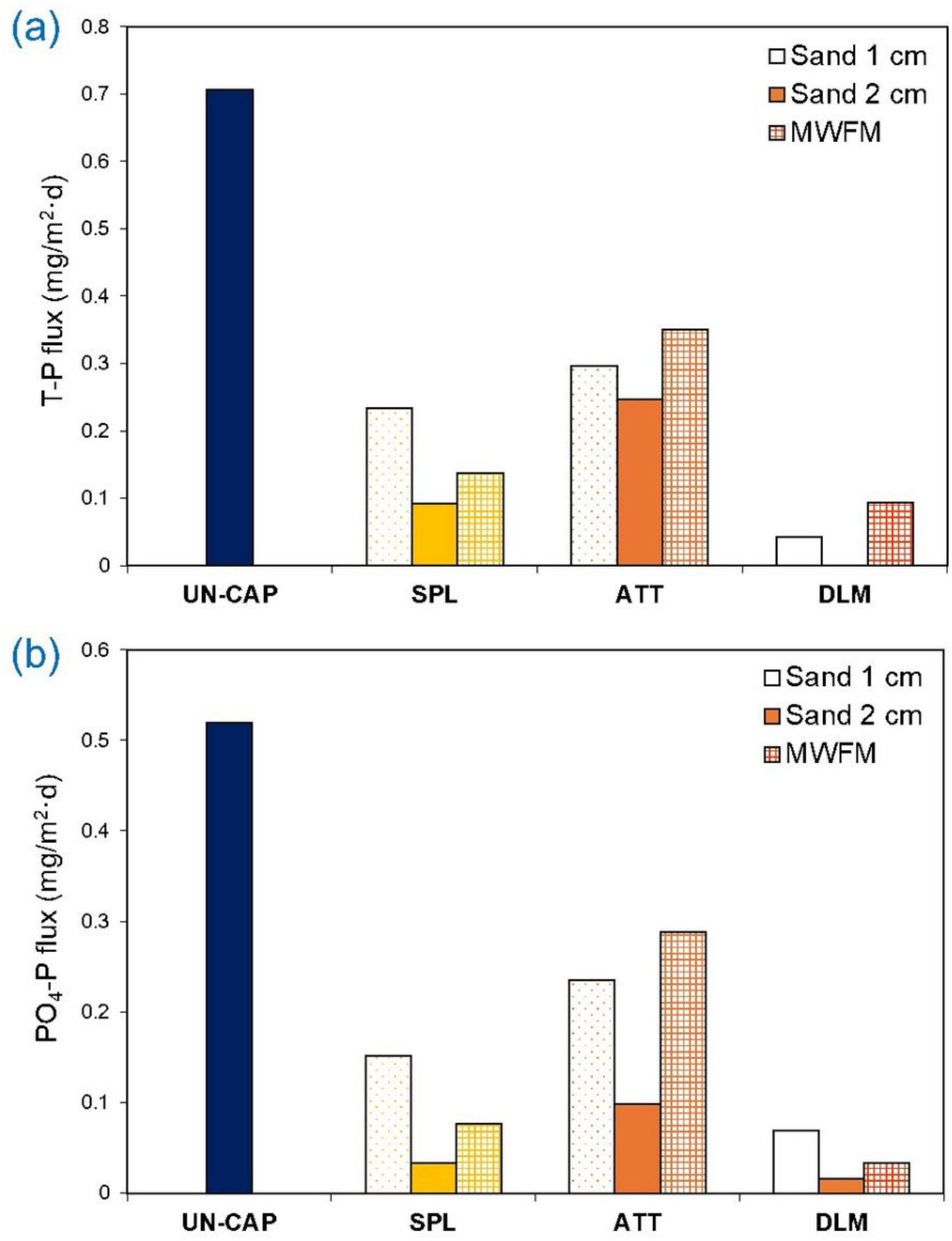

Figure 5 
Flux ( $\mathrm{mg} / \mathrm{m}^{2} \cdot \mathrm{d}$ ) of (a) T-P and (b) $\mathrm{PO}_{4}-\mathrm{P}$ from sediments to overlying water under the uncapped condition and capped conditions with different Ca-rich clay minerals (SPL, ATT, and DLM) and armor materials (S1, S2, and NWFM) during 70 days of laboratory incubations.
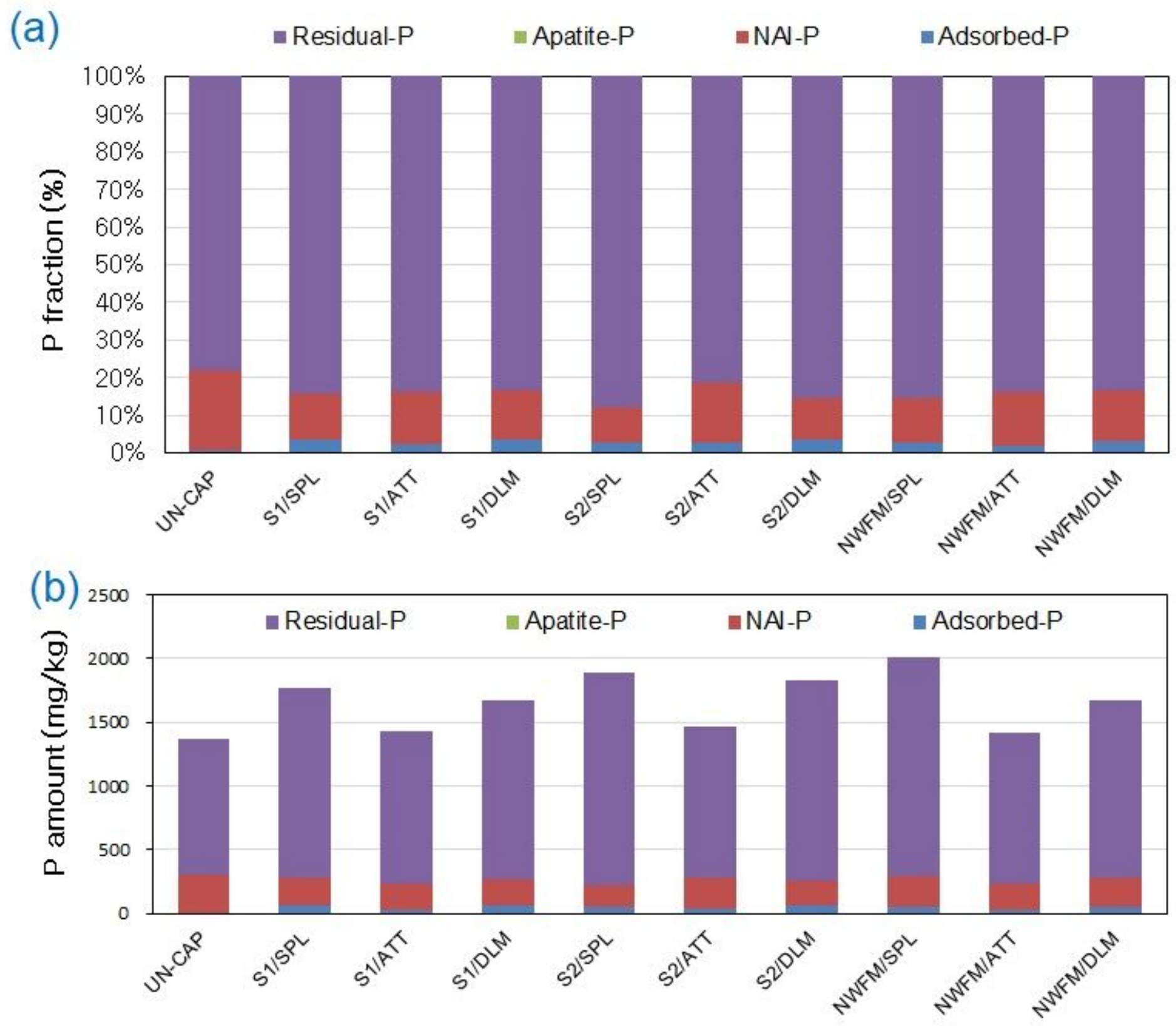

Figure 6

(a) P Fraction (\%) and (b) P amount (mg/g) of Adsorbed-P, NAI-P, Apatite-P, and Residual-P in uncapped sediments and $1 \mathrm{~cm}$ of sediments adjacent to Ca-rich clay minerals (SPL, ATT, and DLM).

\section{Supplementary Files}

This is a list of supplementary files associated with this preprint. Click to download. 
- ESPRCacappingManuscriptSupplementary.docx 